\title{
Transcriptomic insights into the early host- pathogen interaction of cat intestine with Toxoplasma gondii
}

\author{
Meng Wang ${ }^{1}$, Fu-Kai Zhang ${ }^{1}$, Hany M. Elsheikha², Nian-Zhang Zhang ${ }^{1}$, Jun-Jun He ${ }^{1 *}$, Jian-Xun Luo ${ }^{1}$ \\ and Xing-Quan Zhu, ${ }^{1,3^{*}}$
}

\begin{abstract}
Background: Although sexual reproduction of the parasite Toxoplasma gondii exclusively occurs in the cat intestine, knowledge about the alteration of gene expression in the intestine of cats infected with $T$. gondii is still limited. Here, we investigated the temporal transcriptional changes that occur in the cat intestine during $T$. gondii infection.

Methods: Cats were infected with 100 T. gondii cysts and their intestines were collected at 6, 12, 18, 24, 72 and 96 hours post-infection (hpi). RNA sequencing (RNA-Seq) Illumina technology was used to gain insight into the spectrum of genes that are differentially expressed due to infection. Quantitative RT-PCR (qRT-PCR) was also used to validate the level of expression of a set of differentially expressed genes (DEGs) obtained by sequencing.

Results: Our transcriptome analysis revealed 2363 DEGs that were clustered into six unique patterns of gene expression across all the time points after infection. Our analysis revealed 56, 184, 404, 508, 400 and 811 DEGs in infected intestines compared to uninfected controls at 6, 12, 18, 24, 72 and 96 hpi, respectively. RNA-Seq results were confirmed by qRT-PCR. DEGs were mainly enriched in catalytic activity and metabolic process based on gene ontology enrichment analysis. Kyoto Encyclopedia of Genes and Genomes pathway analysis showed that transcriptional changes in the intestine of infected cats evolve over the course of infection, and the largest difference in the enriched pathways was observed at $96 \mathrm{hpi}$. The anti-T. gondii defense response of the feline host was mediated by Major Histocompatibility Complex class I, proteasomes, heat-shock proteins and fatty acid binding proteins.
\end{abstract}

Conclusions: This study revealed novel host factors, which may be critical for the successful establishment of an intracellular niche during T. gondii infection in the definitive feline host.

Keywords: Toxoplasma gondii, Cat, RNA-Seq, Gene expression, Immune response, Xenobiotic metabolism

\section{Background}

Toxoplasmosis, caused by the intracellular parasite Toxoplasma gondii, is a disease of global importance. Toxoplasma gondii has been reported in nearly all warm-blooded animals [1]. However, its only definitive host is the cat, including members of the family Felidae, where the sexual cycle occurs in the enterocytes of the

\footnotetext{
*Correspondence: hejunjun617@163.com; xingquanzhu1@hotmail.com 'State Key Laboratory of Veterinary Etiological Biology, Key Laboratory of Veterinary Parasitology of Gansu Province, Lanzhou Veterinary Research Institute, Chinese Academy of Agricultural Sciences, Lanzhou, Gansu Province 730046, People's Republic of China

Full list of author information is available at the end of the article
}

small intestine. Cat infection occurs via the ingestion of bradyzoite-containing tissue cysts, and following excystation of bradyzoites in the gut, the parasites infect the epithelium and progress from the asexual merozoite stage into sexual stages called gametes (micro- and macrogametocytes). Male and female gametes fuse to form microscopic zygotes/oocysts, which are excreted in cat feces into the environment where they mature into sporulated oocysts [2]. Infected cats can produce millions of oocysts through a single infection [3]. These environmentally resistant oocysts can remain infectious for long periods of time in the environment $[4,5]$. When

(c) The Author(s). 2018 Open Access This article is distributed under the terms of the Creative Commons Attribution 4.0 International License (http://creativecommons.org/licenses/by/4.0/), which permits unrestricted use, distribution, and 
ingested by intermediate hosts, infectious sporozoites are liberated from the oocysts and differentiate into tachyzoites in order to complete the life-cycle.

Humans (an intermediate host) can be infected not only via eating meat containing parasite cysts, but also via accidental ingestion of water contaminated with oocysts [6], ingestion of oocysts in contaminated food sources [7], or via gardening or cleaning cat litter. Although $T$. gondii does not seem to cause major illness in healthy people [8], patients with an immunocompromised status, such as with AIDS or cancer may develop fatal encephalitis, mainly because of the reactivated tissue cysts [9]. Toxoplasma gondii can also cause serious health complications in an unborn child if the primary infection occurred during pregnancy. Other intermediate hosts, such as herbivorous and omnivorous animals, are infected by eating oocysts in contaminated food sources or water supplies [1].

Despite the crucial epidemiological role played by $T$. gondii oocysts in the dissemination of infection to humans and animals [10], studies investigating the gene regulatory pathways that are involved in the early stages of feline intestinal infection and the formation of oocysts are still limited. The intestinal epithelium can function as a physical barrier to protect the host against microbial infection $[11,12]$, and also participates in host innate immunity through the production of cytokines, chemokines and antimicrobial peptides [13-15]. Thus, enhanced understanding of the host-pathogen interactions that permit $T$. gondii to develop into sexual stages in the cat intestine would help advance the development of improved preventative and therapeutic approaches to thwart the infection at the main source in the definitive host.

The lack of knowledge about the transcriptional changes that occur in cat intestine during early stage of $T$. gondii infection has prompted us to map the temporal changes that occur in the cat intestinal transcriptome during the first 96 hours after infection. In this study, we used RNA sequencing to illustrate the transcriptional changes that occur in the intestine of cats during early stages of $T$. gondii infection. Our findings provide new insight into defense strategies in the feline intestine and uncover host genes modulated during infection, including genes required for host defense and genes required for the growth of the parasite.

\section{Methods}

\section{Animals}

Female (2- to 3-month-old) domestic cats (Felis catus) of the Chinese Li Hua breed were purchased from a local breeder and housed in a controlled environment. Prior to the experiment, all cats were confirmed to be negative from $T$. gondii using the modified agglutination test (MAT) and free of major viral infections (e.g. feline immunodeficiency virus, feline parvovirus, feline calicivirus, feline coronavirus and feline leukemia virus) based on serological examination. Cats received commercial cat diets (Royal Canine Inc., St. Charles, USA) and water ad libitum during the two weeks prior to experimentation in order to minimize any potential dietary impact on the study results. After challenging with $T$. gondii, each cat was fed individually once per day based on their daily energy requirements and water was available ad libitum.

\section{Parasite infection and sample collection}

Toxoplasma gondii PRU strain belongs to the predominant genotype II reported in cats [16-18]. The capacity of the PRU strain to produce cysts in the brain of mice and oocysts in the gut of cats makes it a suitable candidate for experimental infections of cats [19]. Toxoplasma gondii PRU strain was maintained by passage through Kunming mice [20]. We used a low passage PRU strain to preserve the biological attributes and fidelity to the original strain. Brain cysts of $T$. gondii were examined microscopically and their number was adjusted to $100 \mathrm{cysts} / \mathrm{ml}$ in phosphate buffered saline (PBS, pH 7.4). Cats $(n=21)$ were randomly allocated to 7 groups (i.e. 3 cats per group). Six groups were subjected to infection, where each cat was infected by intragastric inoculation with 100 cysts in $1 \mathrm{ml}$ sterile PBS. One group of cats (remained uninfected as a control group) received $1 \mathrm{ml}$ of sterile PBS only. Cat intestinal tissue was collected at different time points $[6,12$, 18, 24, 72 and 96 hours post-infection (hpi)] from cats infected with $T$. gondii. Intestinal tissue was also collected from three cats in the uninfected group. The collected tissues were rinsed trice in PBS and kept frozen in liquid nitrogen until further processing.

\section{RNA isolation and quantification}

Total RNA from each intestine was extracted by TRIzol Reagent (Invitrogen Co. Ltd, San Diego, USA). RNA degradation and contamination were examined by electrophoresis on $1 \%$ agarose gels. RNA purity was checked by a NanoPhotometer spectrophotometer (Implen, Westlake Village, CA, USA). RNA concentration was measured using a Qubit $^{\circ}$ RNA Assay Kit in a Qubit 2.0 Fluorometer (Life Technologies, Carlsbad, CA, USA). RNA integrity was assessed using an RNA Nano 6000 Assay Kit and an Agilent Bioanalyzer 2100 system (Agilent Technologies, Santa Clara, CA, USA), demonstrating an RNA integrity number $>8$.

\section{Confirmation of $T$. gondii infection in the intestines}

RNA (1 $\mu \mathrm{g})$ collected at each time point stated above were reverse-transcribed to a single strand cDNA using a PrimeScript ${ }^{\mathrm{tm}}$ RT reagent kit with gDNA Eraster (Takara, Dalian, China). Infection was detected in the intestinal tissues using quantitative real-time PCR 
(qRT-PCR), which targets surface antigen one (SAG1) of T. gondii using forward primer: 5'-CAC AGA GCC TCC CAC TCT TG-3' and reverse primer: 5'-AGA CTA GCA GAA TCC CCC GT-3'. qRT-PCR was performed using a 7500 system (ABI), employing $\mathrm{SYBR}^{\circ}$ Premix Ex $\mathrm{Taq}^{\mathrm{Tm}}$ II (Takara). The reaction was performed in a final volume of $20 \mu \mathrm{l}$ containing 10.4 $\mu \mathrm{l}$ Premix Ex Taq II, 0.8 $\mu \mathrm{l}$ of each primer, $2 \mu \mathrm{l}$ of cDNA template, and $6 \mu \mathrm{l}$ of double-distilled water $\left(\mathrm{ddH}_{2} \mathrm{O}\right)$. PCR conditions were as follows: initial denaturation step at $95^{\circ} \mathrm{C}$ for $30 \mathrm{~s}$, followed by 40 cycles of $95{ }^{\circ} \mathrm{C}$ for $5 \mathrm{~s}$ and $60^{\circ} \mathrm{C}$ for $34 \mathrm{~s}$. All templates were examined in triplicate and controls without template were also included. The results of qRT-PCR were calculated by determination of the $2^{-\triangle \Delta C T}$ (where $C T$ is the threshold cycle) (relative expression) level.

\section{Library preparation for sequencing}

Three micrograms of RNA per intestinal sample were used as an input for the RNA sample preparations. Sequencing libraries were generated using an NEBNext Ultra $^{\text {tx }}$ RNA Library Prep Kit for Illumina ${ }^{\circ}$ (NEB, Ipswich, USA) following manufacturer's recommendations and index codes were added to correlate sequences to their respective samples. The mRNA was purified from total RNA using poly-T oligo-attached magnetic beads. Fragmentation was performed using divalent cations under elevated temperature in NEBNext First Strand Synthesis Reaction Buffer $(5 \times)$. First strand cDNA was synthesized using random hexamer primer and M-MuLV Reverse Transcriptase (RNase H). Second strand cDNA synthesis was subsequently performed using DNA Polymerase I and RNase H. Remaining overhangs were converted into blunt ends via exonuclease/ polymerase activities. After adenylation of the 3 ' ends of DNA fragments, NEBNext Adaptors with a hairpin loop structure were ligated to prepare for hybridization. In order to select cDNA fragments preferentially $150-200$ bp in length, the library fragments were purified with AMPure XP system (Beckman Coulter, Beverly, USA). Then, $3 \mu$ l of USER Enzyme (NEB) were used with size-selected, adaptor-ligated cDNA at $37{ }^{\circ} \mathrm{C}$ for $15 \mathrm{~min}$ followed by $5 \mathrm{~min}$ at $95{ }^{\circ} \mathrm{C}$ before PCR. The PCR was performed with Phusion High-Fidelity DNA polymerase, Universal PCR primers and Index (X) Primer. PCR products were purified (AMPure XP system) and the quality of the libraries was assessed using an Agilent Bioanalyzer 2100 system. The clustering of the index-coded samples was performed on a cBot Cluster Generation System using TruSeq PE Cluster Kit v3-cBot-HS (Illumina, San Diego, USA) according to the manufacturer's instructions.

\section{Differential expression analysis}

Raw reads of fastq format were processed using in-house Perl scripts. Clean reads were obtained by removing reads adapters, poly- $\mathrm{N}$ containing reads and low-quality reads from raw data. The Q20, Q30 and GC content of the clean data were determined. All downstream analyses were based on the clean data. The Felis catus genome was used as the reference genome and gene model annotation files were downloaded from the cat genome website (ftp://ftp.ensembl.org/pub/release-76/ fasta/felis_catus/dna/). Index of the reference genome was built using Bowtie v.2.2.3 and paired-end clean reads were aligned to $F$. catus reference genome using TopHat v.2.0.12. TopHat was selected as the mapping tool since it can produce a database of splice junctions based on the gene model annotation file and provides a better mapping result than other mapping tools [21]. HTSeq v.0.6.1 was used to count the read numbers mapped to each gene. Fragments per kilobase of transcript sequence per million base pairs sequenced (FPKM) of each gene was calculated in order to determine the level of gene expression. Differential expression analysis of two groups (three replicates per group) was performed using the DESeq $\mathrm{R}$ package (1.18.0) [22]. The $P$-values were adjusted using the Benjamini-Hochberg correction for multiple testing. Genes were determined to be significantly differentially expressed if they had a $\mid \log 2$ (fold change) $\mid>0.58$ and false-discovery rate $(\mathrm{FDR})<0.05$.

Pearson's correlation analysis of samples used for RNA sequencing was carried out to examine the correlation between gene expression levels among samples. The square of the Pearson's correlation coefficient $\left(R^{2}\right)<0.92$ indicates optimal sampling selection and experimental conditions. The distribution of differentially expressed genes (DEGs) on the chromosomes of cat genomes was examined. Clustering analysis of the DEGs was performed to determine the co-expression pattern of genes at different time points after infection. The genes with the same or similar expression pattern were grouped together into a cluster. $K$-means cluster was achieved based on the relative expression level of DEGs $\log _{2}$ (fold change).

\section{Gene Ontology (GO) and Kyoto Encyclopedia of Genes and Genomes (KEGG) analysis}

GO enrichment analysis of DEGs was carried out using the GOseq $\mathrm{R}$ package [23]. All DEGs were mapped to GO terms in the database (http://www.geneontology.org/), and then gene numbers were calculated for every GO term using the hypergeometric test in order to obtain the significantly enriched GO terms for the DEGs; these were compared to the genomic background. GO terms with a corrected $P$-value less than 0.05 were considered significantly enriched by DEGs. KOBAS software was used to perform pathway analysis and to test the statistical enrichment of the DEGs in KEGG (http:// www.genome.jp/kegg/) [24, 25]. This analysis was used 
to identify significantly enriched genes involved in metabolic or signalling pathways.

\section{Validation of the RNA-Seq data}

The expression of 10 to 14 selected genes was investigated by qRT-PCR to confirm the RNA sequencing based transcriptional response of cat intestine to $T$. gondii infection. These genes were identified by sequencing analysis as differentially upregulated or downregulated following the infection. Total RNA was isolated from the intestinal tissues obtained from T. gondii-infected and uninfected (control) cats at different time points after infection using RNeasy Mini Kit (Qiagen, Hilden, Germany). DNase-digested total RNA $(1 \mu \mathrm{g})$ was reverse-transcribed to single strand cDNA using the Primer Script ${ }^{\mathrm{tm}}$ RT Reagent Kit with gDNA Eraser (Takara). SYBR Premix Ex Taq ${ }^{\text {mi }}$ II (Takara) was used to perform qRT-PCR on an ABI real-time PCR cycler (ABI 7500). Forward (F) and reverse (R) primers used to amplify the selected genes are listed in Table 1. The amplification reactions were performed using the following conditions: $95{ }^{\circ} \mathrm{C}$ for $10 \mathrm{~min}$ followed by 40 cycles of $95{ }^{\circ} \mathrm{C}$ for $15 \mathrm{~s}$ and $60{ }^{\circ} \mathrm{C}$ for $1 \mathrm{~min}$. Melting curve analysis was performed using the following conditions: $1 \mathrm{~min}$ at $95^{\circ} \mathrm{C}, 65^{\circ} \mathrm{C}$ for $2 \mathrm{~min}$ and progressive increase from 65 to $95{ }^{\circ} \mathrm{C}$ to ensure that a single product was amplified in each reaction. The relative fold change in gene expression was calculated following actin normalization using the $2^{-\Delta \Delta C T}$ method. The mean values of the control cats were used to calculate the fold change for the infected cats.

\section{Results}

\section{Confirmation of $T$. gondii infection}

Detection and amplification of T. gondii SAG1 gene was confirmed in all infected cats by qRT-PCR assay. The three cats in the control group were qRT-PCR-negative. The results also revealed that $S A G 1$ gene was amplified in intestinal samples of cats starting from $6 \mathrm{hpi}$ and peaking at 96 hpi.

\section{RNA-Seq data}

We employed RNA-Seq to investigate the temporal gene expression patterns of cat intestine during early infection with $T$. gondii PRU strain. Over 25,000,000 raw reads were obtained from each intestinal sample and more than 24,000,000 clean reads were obtained after removing adaptors and low-quality reads. About $83 \%$ of the clean reads were mapped to the reference genome and more than $70 \%$ of the clean reads were located in the exon regions; the rest were in the introns or intergenic. Pearson's correlation coefficient of gene expression among different time points was close to 1 , indicating the high similarity of the gene expression patterns between samples (Fig. 1). The distribution of DEGs on cat chromosomes is shown in Fig. 2. The chromosomal location of DEGs across the different time points after infection showed more upregulated gene expression on chromosomes D2, D3 and E2, and a skewed pattern of downregulated genes on the $\mathrm{X}$ chromosome (Additional file 1: Table S1).

\section{Gene expression analysis}

Differential gene expression analysis was performed by comparing the gene transcriptional level in response to T. gondii infection to that in the uninfected control samples at each time point after infection (FDR $<0.05$ and $\mid \log 2$ (fold change) $\mid>0.58$ ). Transcriptome analysis revealed 2363 infection-specific DEGs, of which 56, 184, 404, 508, 400 and 811 genes were differentially expressed at $6,12,18,24,72$ and 96 hpi, respectively (Fig. 3, Additional file 2: Table S2). qRT-PCR results of the examined set of genes at $6,12,18,24,72$ and 96 hpi in cat intestine were consistent with the RNA-Seq results, confirming the validity of sequencing data (Fig. 4).

\section{Cluster analysis}

Hierarchical cluster analysis using k-means grouped all DEGs into six clusters according to their expression pattern across the six time points post-infection (Fig. 5). Cluster 1 (containing 433 genes) and cluster 3 (127 genes) showed a progressive increase in the expression with time after infection. Genes in cluster 2 (409 genes) and cluster 4 ( 214 genes) were downregulated as T. gondii infection proceeds. Cluster 5 (38 genes) and cluster 6 (15 genes) showed a bi-phasic upregulated expressional pattern, but at different time points after infection. Venn diagram analysis revealed 70 genes that were differentially co-expressed in infected samples at all time points $(12,18$, 24, 72 and 96 hpi) compared with control samples (Fig. 6). The highest number of specific DEGs was detected at 96 hpi (347), which was significantly higher than that of any other time point. The number of DEGs from 72 and 96 hpi were less than that from 24 and 96 hpi. The mechanisms that underpin these temporal changes of gene expressions remain to be investigated. These aforementioned results indicate that most of the upregulated genes were grouped in clusters 1,3 and 5, whereas clusters 2 and 4 contained most of the downregulated genes.

\section{Gene ontology (GO) classifications}

GO analysis showed that DEGs were overrepresented by GO terms involved in immune responses, such as chemokine receptor binding and cytokine activity. The top 30 differentially expressed GO terms of the DEGs in cat intestine are shown in Table 2. GO analysis of DEGs at various time points post-infection revealed the dynamic changes in biological processes, molecular function and cellular component during early stages of $T$. gondii infection in the cat intestine. The top 30 most enriched GO terms with the corresponding 
Table 1 Primers used in the GRT-PCR in the present study

\begin{tabular}{|c|c|c|c|c|c|}
\hline Gene & Sequence $\left(5^{\prime}-3^{\prime}\right)$ & Primer length (mer) & $\operatorname{Tm}\left({ }^{\circ} \mathrm{C}\right)$ & GC \% & Product length (bp) \\
\hline \multirow[t]{2}{*}{$\beta$-actin } & ATTCCACGGCACAGTCAAGG & 20 & 63.39 & 55 & 110 \\
\hline & CACCAGCATCACCCCATTT & 19 & 61.75 & 52.63 & \\
\hline \multirow[t]{2}{*}{ RSAD2 } & CACCAGCGTCAACTACCACT & 20 & 59.97 & 55 & 140 \\
\hline & AATATTCACCGGCTTCCTGC & 20 & 58.32 & 50 & \\
\hline \multirow[t]{2}{*}{ SYCN } & AAGACGCGCAAGTTCTCGAC & 20 & 61.28 & 55 & 117 \\
\hline & AAGGCATCAGTAACACCTGCAA & 22 & 60.49 & 45.45 & \\
\hline \multirow[t]{2}{*}{ CELA1 } & ATGCTACGCTTCTTGGTGCT & 20 & 60.04 & 50 & 239 \\
\hline & CGGAAGGTCATITTGCGGTC & 20 & 59.83 & 50 & \\
\hline \multirow[t]{2}{*}{ GKN2 } & CTTGAAGGTGGTATGCCTGGT & 21 & 60 & 52.38 & 214 \\
\hline & CCTGGATGCGATGTAGCGAT & 20 & 60.04 & 55 & \\
\hline \multirow[t]{2}{*}{ TFF2 } & ATGCGTCATGGAAGTCTCGG & 22 & 62.14 & 50 & 198 \\
\hline & TGACAGTCGTCAACGGACATC & 24 & 61.04 & 45.83 & \\
\hline \multirow[t]{2}{*}{ LYPF } & TTACACCCGACAAACCCTGA & 20 & 59.24 & 52.38 & 132 \\
\hline & CAGGTCTCCGGCCTITATTCT & 21 & 60.67 & 55 & \\
\hline \multirow[t]{2}{*}{ CYP1A1 } & TCGATACCTACCCAACCCTG & 20 & 58.22 & 55 & 246 \\
\hline & ACTGTGTCAAATCCAGCTCCG & 21 & 60.61 & 52.38 & \\
\hline \multirow[t]{2}{*}{ CLPS } & TGCTCTGCCAAGACACTCTAT & 21 & 58.82 & 47.62 & 222 \\
\hline & 5'CAATCAGACAAGGGAGGTGCT & 21 & 60 & 52.38 & \\
\hline \multirow[t]{2}{*}{ CPA2 } & TGCTCAGTCATCTACCAAGCC & 21 & 59.79 & 52.38 & 100 \\
\hline & ATCGACCTGTGTCCCTCAGT & 20 & 60.25 & 55 & \\
\hline \multirow[t]{2}{*}{ PRSS2 } & TACTTCTGCCGCCATGACTC & 20 & 59.82 & 55 & 227 \\
\hline & TCACTTGGATGCGAGACTTGT & 21 & 59.66 & 47.62 & \\
\hline \multirow[t]{2}{*}{ CPA1 } & AACGATTTACCAAGCCAGCGG & 21 & 61.55 & 52.38 & 210 \\
\hline & GCCGAAGGACCAGTTCAGTA & 20 & 59.39 & 55 & \\
\hline \multirow[t]{2}{*}{ FLNC } & AGTGGTGCCACCCTGTAACC & 20 & 62.06 & 60 & 181 \\
\hline & СTCTCGCACTITCACTGGCT & 20 & 60.32 & 55 & \\
\hline \multirow[t]{2}{*}{ FN1 } & GAACACTAATGTCAACTGCCCA & 22 & 58.85 & 45.45 & 125 \\
\hline & TGGACCTTGGCAGAGAATCC & 20 & 59.38 & 55 & \\
\hline \multirow[t]{2}{*}{ DES } & ATGTCCAAGCCAGACCTCAC & 20 & 59.67 & 55 & 240 \\
\hline & GGAATCGTTGGTGCCCTTGA & 20 & 60.61 & 55 & \\
\hline \multirow[t]{2}{*}{ ACTG2 } & GTATACTCGGTGCTCAAGCC & 20 & 58.15 & 55 & 243 \\
\hline & TAGGATCCCTCGCTTGCTCT & 20 & 60.11 & 55 & \\
\hline \multirow[t]{2}{*}{ FABP6 } & CCCACAGCTACCAACGCTAC & 20 & 60.74 & 60 & 185 \\
\hline & ATTCTGCTGGAGAGCATCTTCAAT & 24 & 60.39 & 41.67 & \\
\hline \multirow[t]{2}{*}{ MYH11 } & GCATGCTGCAAGATCGAGAG & 20 & 59.42 & 55 & 147 \\
\hline & CTTGCGTGATGCTTGTGTCC & 20 & 60.11 & 55 & \\
\hline \multirow[t]{2}{*}{ FGB } & CCCAATCAACCTTCGTGTGC & 20 & 59.76 & 55 & 156 \\
\hline & TCCTCACATTCTITGCCAGACA & 22 & 59.89 & 45.45 & \\
\hline \multirow[t]{2}{*}{ TAGLN } & AACGGCGTGATTCTGAGCAA & 20 & 60.23 & 47.2 & 158 \\
\hline & CCACCTGCTCCATTTGCTTG & 21 & 59.78 & 50 & \\
\hline \multirow[t]{2}{*}{ ALPI } & ACACACCTCATGGGCCTCTT & 20 & 61.14 & 55 & 199 \\
\hline & TCAGTGCCAGATAAGCCCTG & 20 & 59.46 & 55 & \\
\hline \multirow[t]{2}{*}{ CNN1 } & TGGCATCATTCTTTGCGAGTTC & 22 & 59.84 & 45.45 & 153 \\
\hline & TCGAAAATGTCGTGGGGCTT & 20 & 60.25 & 50 & \\
\hline
\end{tabular}


Table 1 Primers used in the qRT-PCR in the present study (Continued)

\begin{tabular}{|c|c|c|c|c|c|}
\hline Gene & Sequence $\left(5^{\prime}-3^{\prime}\right)$ & Primer length (mer) & $\operatorname{Tm}\left({ }^{\circ} \mathrm{C}\right)$ & GC \% & Product length (bp) \\
\hline \multirow[t]{2}{*}{ LYPD2 } & TGAGATGCTACACCTGTCACG & 21 & 59.80 & 52.38 & 123 \\
\hline & AGAAGGGGTACACTATCTCCAAG & 23 & 58.71 & 47.83 & \\
\hline \multirow[t]{2}{*}{ pCREB } & CCACAACCATCCGTCCTTCT & 20 & 62.26 & 55 & 137 \\
\hline & TGTGTGTGTGTGTGTCGGTATGT & 23 & 62.26 & 47.83 & \\
\hline \multirow[t]{2}{*}{ MMP } & GACGACGATGAGCTGTGGA & 19 & 61.02 & 57.89 & 115 \\
\hline & TGGTGTATTCCTTGCCGTTG & 20 & 61.85 & 50 & \\
\hline \multirow[t]{2}{*}{ FABP1 } & CTGATGAAGGTGCCAAGAACAA & 22 & 62.46 & 45.45 & 132 \\
\hline & GCATTTCCTCACTATTTCCCACTC & 24 & 62.3 & 45.83 & \\
\hline
\end{tabular}

Abbreviation: Tm, melting temperature

number of genes at each time point after infection are shown (Fig. 7). Catalytic activity and metabolic process were the most significantly enriched GO terms in molecular function category and biological process category, respectively. This finding was consistently observed in all of the six groups $(6,12,18,24,72$, and $96 \mathrm{hpi}$ ) compared to the uninfected control group, suggesting that these processes play fundamental roles in feline response to infection with this parasite.

\section{Functional analysis of the transcriptional response of cat} intestine to $T$. gondii infection

Compared to controls, 145 genes were assigned to 62 pathways at $6 \mathrm{hpi}, 386$ genes were involved in 141 pathways at $12 \mathrm{hpi}, 674$ genes were involved in 201 pathways at $18 \mathrm{hpi}, 890$ genes were involved in 206 pathways at $24 \mathrm{hpi}, 673$ genes were involved in 189 pathways at $72 \mathrm{hpi}$, and 1321 genes were involved in 238 pathways at $96 \mathrm{hpi}$. The top 20 most overrepresented pathways in each group are shown in Fig. 8 . Interestingly, pathways related to metabolism were enriched in samples from all time points except at 6 hpi. These results agree with the results of GO analysis of DEGs and show that fewer host pathways were identified within $6 \mathrm{~h}$ of infection to be uniquely affected by T. gondii infection. As shown in Table 3, 36 KEGG pathways were differentially expressed in cat intestine following $T$. gondii infection.

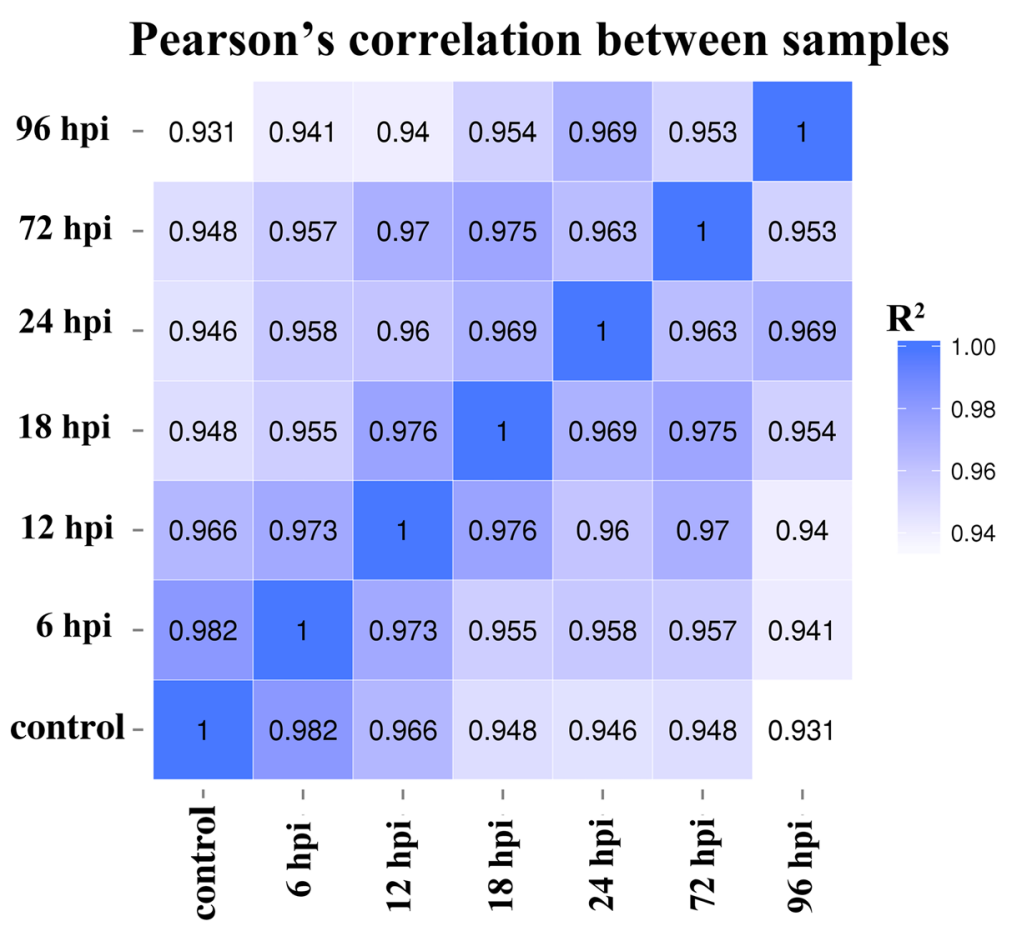

Fig. 1 A heatmap showing the magnitude of the Pearson's correlation coefficient matrix among different groups. The map shows that all correlations in this matrix are positive and of moderate to large value. Variables: 0 (control), 6, 12, 18, 24, 72 and 96 hours post-infection 


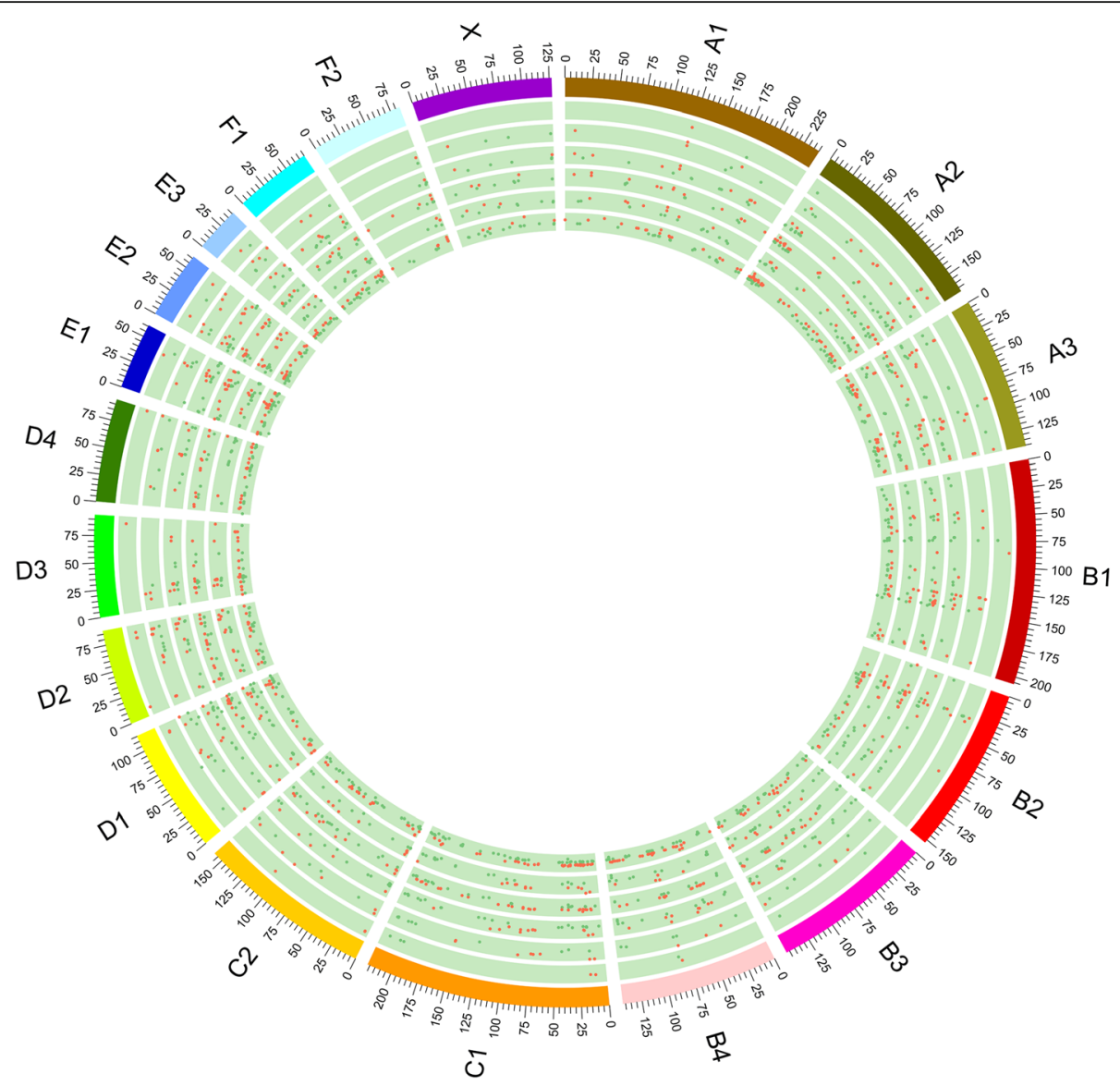

Fig. 2 Chromosomal position of the differentially expressed genes (DEGs) implicated in T. gondii interaction with cat intestine. Circos plot shows the relative expression levels of DEGs in the cat chromosomes. Up- and downregulated genes were found on all cat chromosomes; however, the DEGs encoded by chromosome $X$ were mainly downregulated. Chromosome number and bands are identified in the outermost ring. Other tracks from outer to inner compares the cat intestinal transcriptional response to $T$. gondii infection at 6, 12, 18, 24, 72 , and 96 hours postinfection. Red and green color represents the upregulated and downregulated genes, respectively

\section{Discussion}

This study aimed to investigate how gene expression in the cat intestine is altered during early infection with $T$. gondii. We used RNA sequencing analysis to determine any temporal changes in the transcriptional response of the intestine of cats infected with T. gondii at $6,12,18,24,72$ and 96 hpi. Our results showed that 2363 genes were differentially expressed in the intestine of infected cats compared to uninfected control cats.

GO enrichment and KEGG pathway analyses showed that DEGs involved in the metabolic process and catalytic activity were the most enriched at all time points post-infection. A previous study has reported the upregulation of cell growth/maintenance (Translation and Transcription GO categories) and metabolism (Glycolysis and TCA Cycle GO categories)-related genes in the T. gondii merozoite stage during intestinal infection of mice [26]. This intraepithelial intestinal stage of $T$. gondii proliferates asexually using endopolygeny, whereby multiple daughters are generated from a single parental organism [27]. The results of the present and previous studies underscore the high bioenergetic demands of the growing parasite, in order to adapt to the low oxygen tension in the cat's intestine, and sustain its proliferation [28].

Our results also showed the downregulation of genes involved in the class I major histocompatibility complex (MHC I) pathway, at 6 and 12 hpi. MHC I is composed of the polymorphic heavy chain, $\beta 2$-microglobulin, and antigenic peptides. The latter can be derived from endogenous proteins and from proteins of this intracellular parasite. These proteins are degraded by the proteolytic proteasome complex, then transported into the endoplasmic reticulum (ER) where they associate with the class I molecule to form MHC I. One of the physiological functions of MHC I is recognition by the peptide-specific T-cell receptors of cytolytic $\mathrm{T}$ lymphocytes (CTLs). These 

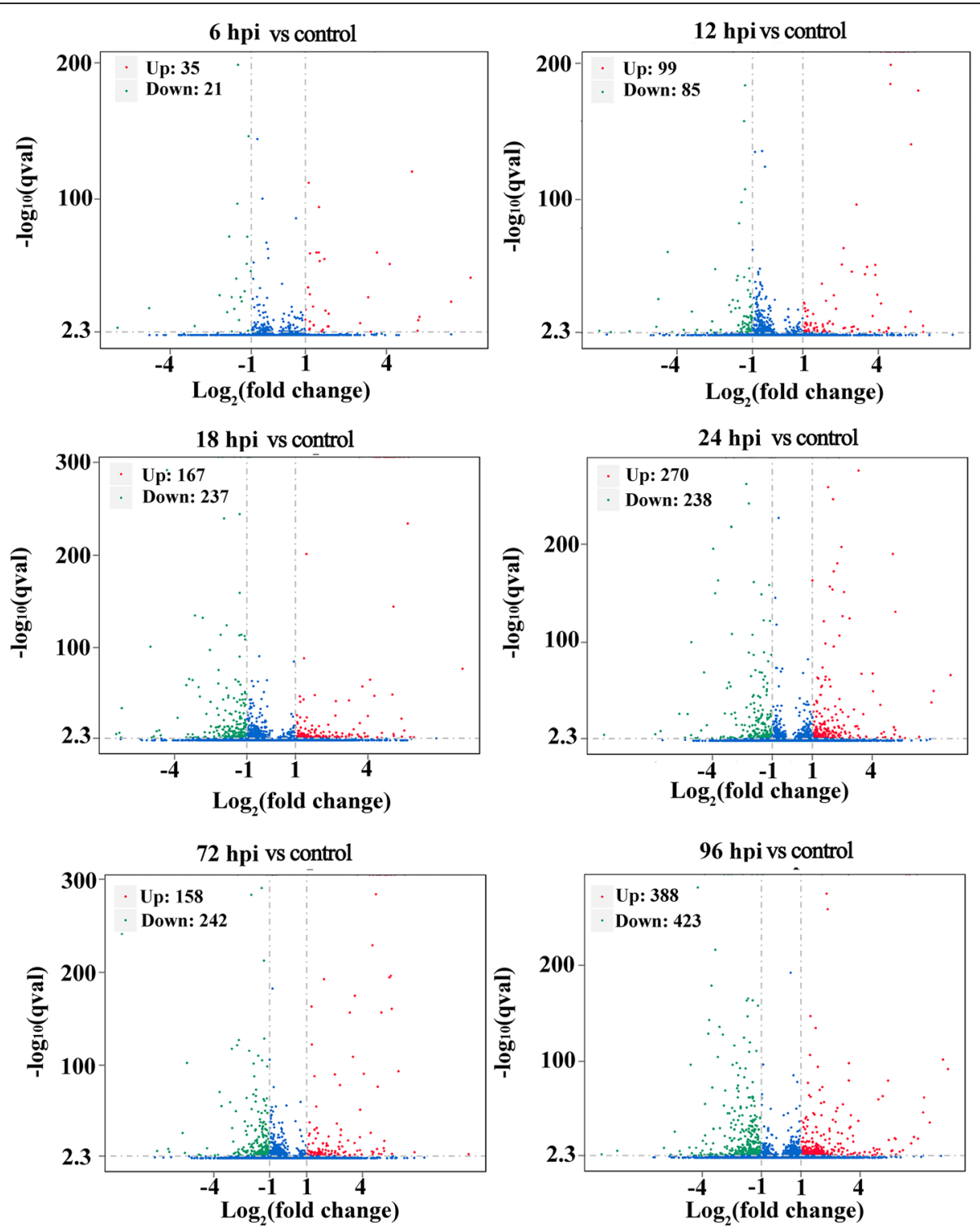

Fig. 3 Volcano plots showing the transcriptional response of cat intestine to infection with $T$. gondii PRU strain at each of the indicated time points after infection compared to those of the uninfected controls. Differentially expressed genes (DEGs) are shown as red (upregulated) or green (downregulated) dots. Non-significant difference between the expressions of genes is indicated by blue dots. The X-axis represents the value of $\log _{2}$ (fold change) and the $Y$-axis shows the value of - $\log _{10}$ (qval)

cells are known to play critical roles in controlling $T$. gondii infection, by limiting the reactivation of latent infection and parasite proliferation during acute infection [29-31]. CTLs eliminate infected cells by recognition of foreign antigens that are processed in a proteasome-dependent pathway and presented by MHC I [32]. Therefore, the downregulation of MHC I genes during the first 12 hours after infection can reduce the antigen-specific CTL cell-mediated killing of T. gondii-infected cells [33]. Interferon gamma (IFN- $\gamma$ ) plays a critical role in innate immunity during acute T. gondii infection [34]. PA28, a proteasome activator induced by IFN- $\gamma$, has been implicated in MHC I antigen processing. The upregulation of the PA28 gene, observed at $24 \mathrm{hpi}$, indicates that levels of this IFN- $\gamma$-inducible activator protein, PA28, had increased to enhance the cat's defense response. PA28 promotes antigen processing and presentation, through recruiting more immunoproteasomes to proteasomes, and processing more parasite antigens during acute infection [35, 36]. Antigenic peptides resulting from proteasomal degradation are translocated 


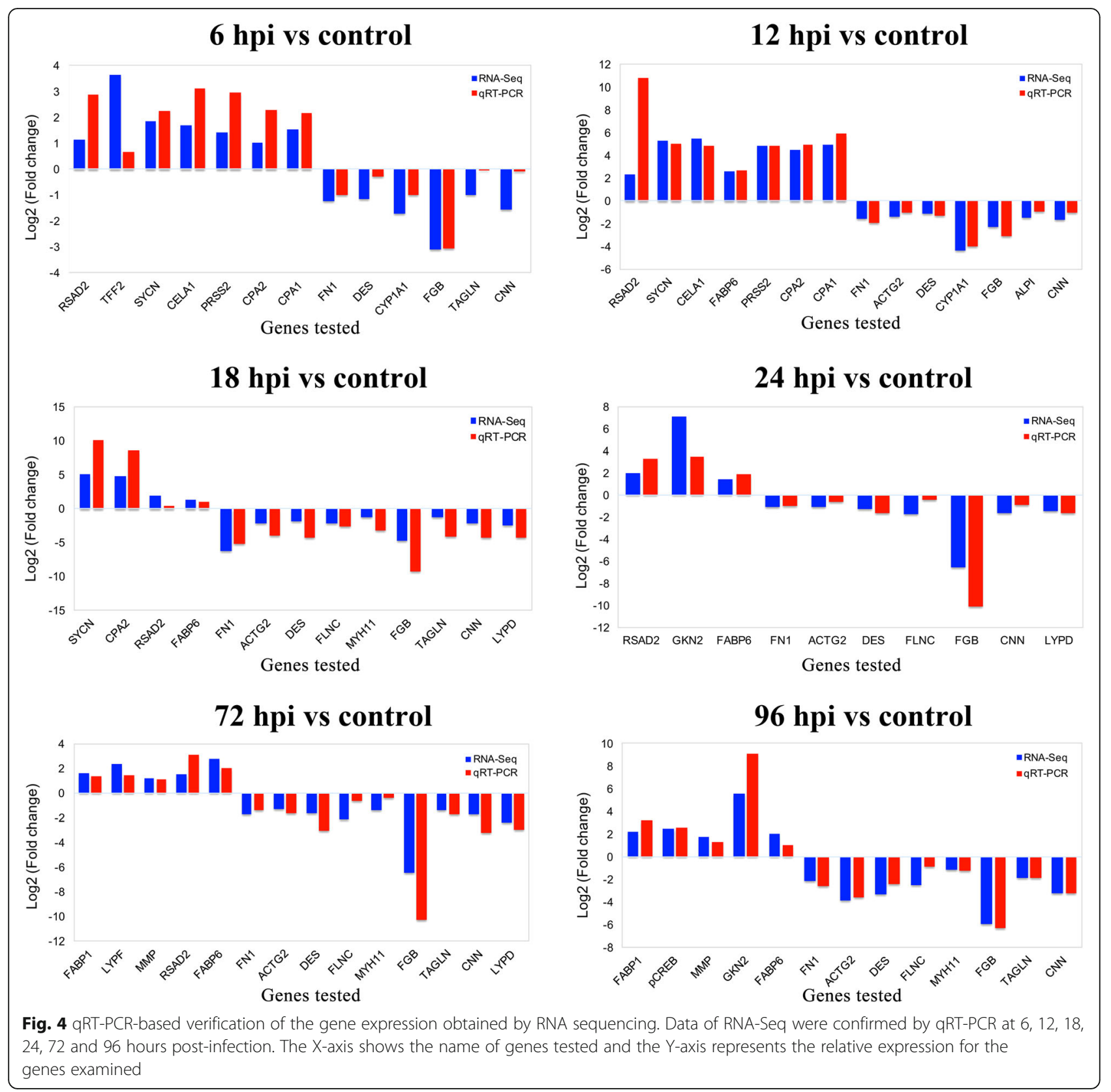

into the ER lumen via transporters associated with antigen processing (TAP1/2) [37]. Therefore, the upregulation of the TAP1/2 gene, observed at $24 \mathrm{hpi}$, may have also enhanced the cats' intestinal immune response to T. gondii infection.

The molecular chaperones heat-shock proteins (HSPs) can stimulate cells of the innate immune response by serving as 'danger'-signaling molecules [38]. After HSP70 binds to the surface of antigen presenting cells, MHC I presentation of the HSP-bound cytosolic antigen occurs, mediated by a transporter associated with antigen processing (TAP) [39]. We did not find any significant changes in the regulation of MHC I gene expression at 18 and $24 \mathrm{hpi}$; however, hsp70 and hsp 90 genes were upregulated at both time points, in addition to PA28 and TAP1/2 genes at 24 hpi. HSP70 and HSP90 are peptide-binding proteins, and are associated with antigenic epitopes [40]. The upregulation of the HSP70/ HSP90 complex may support the immune response, through enhancing antigen processing and presentation via proteasome and enhancing cell viability. $h s p 70$ is expressed in response to a variety of pathological stimuli, and allows the cell to survive lethal insults [41]. The interplay between HSP70 and HSP90 is of crucial 

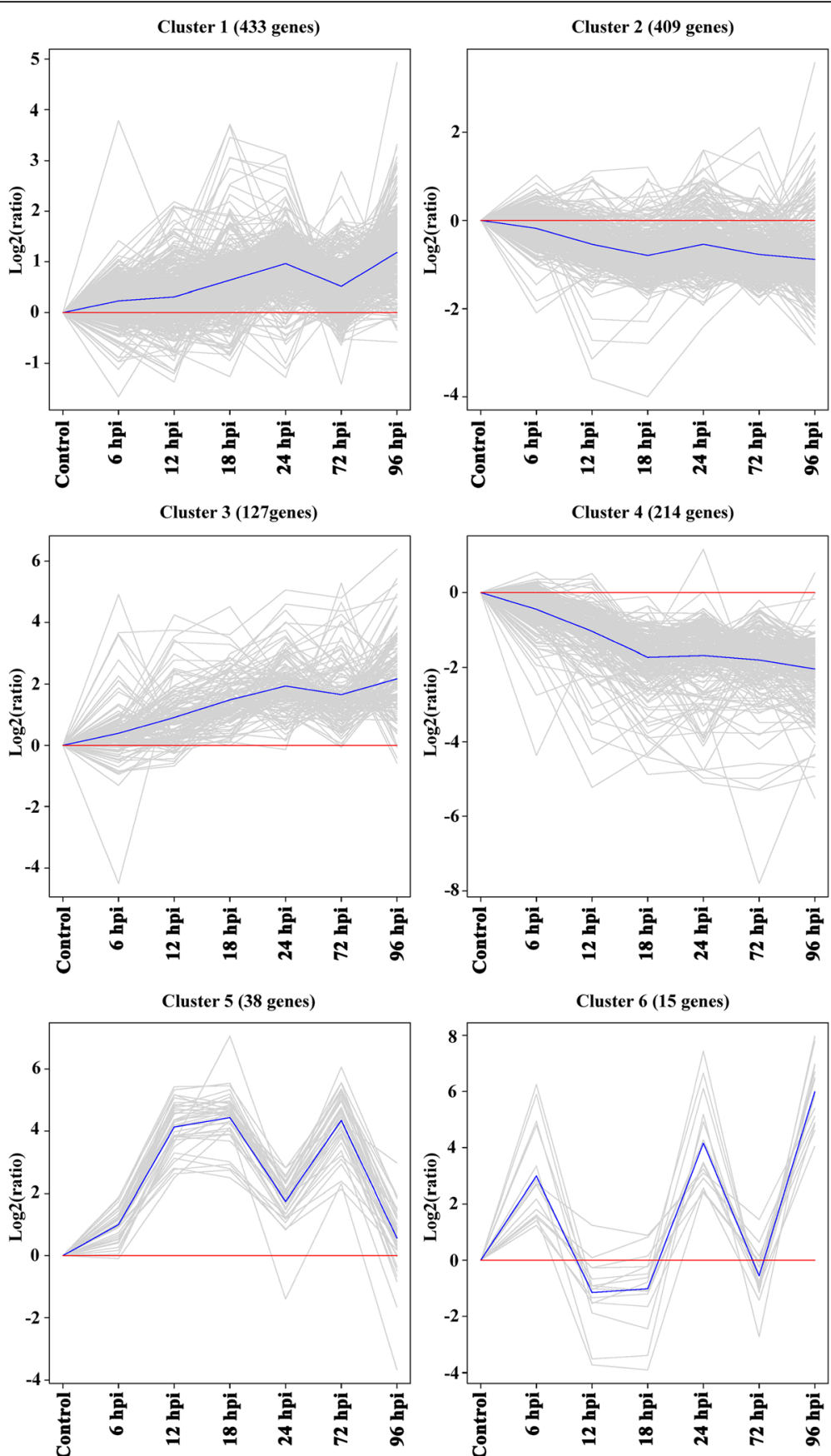

Fig. 5 Expression pattern clustering from RNA-Seq analysis of 2363 DEGs in the intestine of cats infected with T. gondii. Differentially expressed, co-regulated genes from adjacent stage pairwise comparisons were analyzed using k-means clustering. The identified DEGs were grouped into 6 clusters based on the similarity of their expression. The six clusters are shown in a graphical format based on the pattern of expression at different time points after infection. The $\mathrm{X}$-axis represents time points after infection and the $\mathrm{Y}$-axis indicates the relative gene expression

importance for cell viability [42]. Toxoplasma gondii may benefit from the upregulation of $h s p 70$, by maintaining the integrity of surrogate host cells, in order to complete its own growth, and to evade immunological detection. A connection between the upregulation of
HSP genes and the division of schizont nucleoli has been suggested as nuclear division was not detected after 24 hpi in cat intestine [43].

These results support the hypothesis that T. gondii, through the downregulation of $\mathrm{MHCI}$ - related genes 


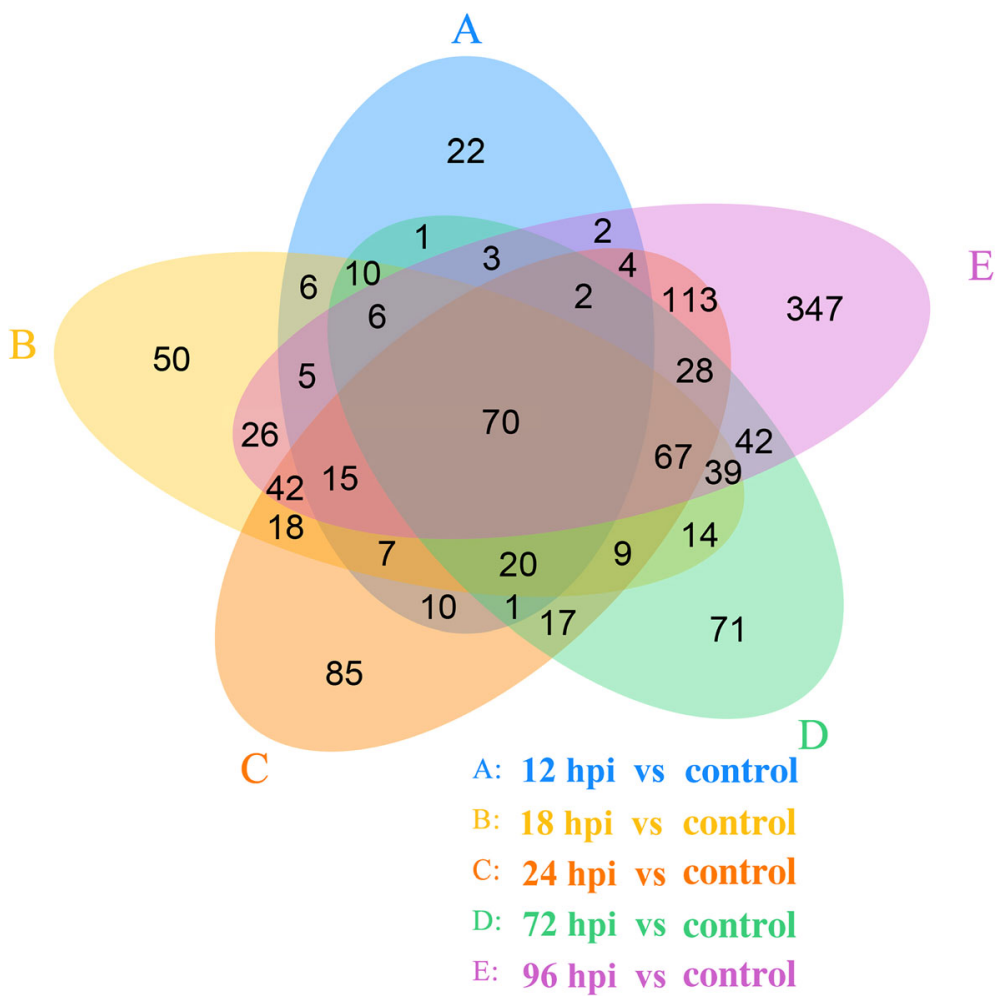

Fig. 6 Venn diagram depicting the respective unique and shared differentially expressed genes among five Toxoplasma gondii-infected groups at $12,18,24,72$ and 96 hours post-infection. The result of 6 hpi was not shown because this two-dimensional diagram could not display more than five comparisons

evades the immune response in order to facilitate its own growth in the intestine of cats during the first 12 hpi. Host cells, via increasing the expression of HSP70/ 90, PA28, TAP, and TAP1/2 genes, deploy chaperones, immunoproteasomes and transporters to limit infection, through promoting antigen processing and presentation. In the present study, as infection progressed, the expression of MHC I genes was elevated at 72 and $96 \mathrm{hpi}$, indicating that the cats may have mounted a CTL response, mediated by MHC I, to limit replication of the parasite. Infecting cultured rat-intestinal epithelial cells with mature sporozoites, induced an elevated expression of genes associated with tumor necrosis factor alpha (TNF $\alpha$ ) signaling, via NF- $k B$ [44]. This transcriptomic change was not observed in our study, suggesting that anti- $T$. gondii intestinal immunity can vary between different hosts and different parasite stages, and based on whether the infection was established under in vitro or in vivo conditions.

Fatty acid binding proteins (FABPs) are released from the cytoplasm following the loss of enterocyte membrane integrity. Toxoplasma gondii can damage cell integrity, leading to the release of FABPs into the circulatory system. Ileal FABP (Il-FABP), which is located at the distal part of the small intestine, can mediate the uptake of fatty-acids. Peroxisome proliferator-activated receptors (PPARs) are activated by fatty acids and their derivatives. Il-FABP was upregulated in the intestine of cats from 12 to $96 \mathrm{hpi}$, but was downregulated at $6 \mathrm{hpi}$. This suggests a correlation between infection-induced alterations in the expression of FABP, and its potential lipid-metabolizing capacity [45] on the activation of PPARs, and the subsequent influence on key biological processes, such as the regulation of glucose, lipid homeostasis, cell survival, inflammation, proliferation and differentiation.

Through metabolic activation caused by phase I enzymes in conjugation with phase II enzymes, xenobiotic compounds such as drugs and chemical pollutants can be eliminated in the urine or bile by phase III transporters [46]. Phase I enzymes include the cytochrome P450 (CYP) superfamily, whereas phase II conjugating enzymes include some enzyme superfamilies; for example sulfotransferase, glutathione S-transferase (GST) and uridine diphosphate-glucuronosyltransferase (UGT). Some CYPs, for example CYP1A1, CYP1A2, CYP1B1 and CYP2A6, are procarcinogen-bioactivating enzymes. By metabolizing xenobiotics into reactive 
Table 2 The top 30 differentially expressed GO terms between T. gondii-infected and uninfected cats

\begin{tabular}{|c|c|c|c|c|c|c|c|c|}
\hline \multirow[t]{2}{*}{ GO category } & \multirow[t]{2}{*}{ GO name } & \multicolumn{6}{|c|}{ Gene number } & \multirow{2}{*}{$\begin{array}{l}\text { FDR } \\
\text { corrected } \\
P \text {-value }\end{array}$} \\
\hline & & Cluster 1 & Cluster 2 & Cluster 3 & Cluster 4 & Cluster 5 & Cluster 6 & \\
\hline \multirow[t]{3}{*}{ Biological process } & Carbohydrate_metabolic_process & 22 & 28 & 4 & 27 & 1 & 0 & $2.03 E-04$ \\
\hline & Cellular amino acid metabolic process & 20 & 8 & 8 & 6 & 0 & 0 & 0.014098 \\
\hline & tRNA metabolic process & 20 & 5 & 5 & 3 & 0 & 0 & 0.04415 \\
\hline \multirow[t]{5}{*}{ Cellular component } & Extracellular region & 30 & 27 & 38 & 6 & 11 & 2 & $3.84 \mathrm{E}-04$ \\
\hline & Extracellular matrix & 7 & 7 & 14 & 0 & 3 & 0 & 0.018194 \\
\hline & Extracellular matrix component & 1 & 4 & 10 & 0 & 1 & 0 & 0.014935 \\
\hline & Myosin complex & 6 & 2 & 8 & 0 & 1 & 0 & 0.021049 \\
\hline & Extracellular region part & 13 & 11 & 19 & 0 & 5 & 0 & 0.022411 \\
\hline \multirow[t]{22}{*}{ Molecular function } & Catalytic activity & 194 & 93 & 182 & 19 & 40 & 5 & $4.44 \mathrm{E}-16$ \\
\hline & Hydrolase activity & 95 & 52 & 93 & 15 & 13 & 3 & $3.02 \mathrm{E}-10$ \\
\hline & lon binding & 137 & 49 & 117 & 6 & 23 & 1 & 0.044804 \\
\hline & Nucleotide binding & 94 & 16 & 48 & 2 & 11 & 0 & 0.008417 \\
\hline & Small molecule binding & 99 & 19 & 55 & 3 & 12 & 0 & 0.001499 \\
\hline & Anion binding & 92 & 18 & 49 & 1 & 10 & 1 & 0.020323 \\
\hline & Carbohydrate derivative binding & 83 & 16 & 42 & 3 & 10 & 0 & 0.026838 \\
\hline & Pyrophosphatase activity & 52 & 6 & 24 & 0 & 4 & 0 & 0.030815 \\
\hline & Nucleoside-triphosphatase activity & 51 & 6 & 23 & 0 & 4 & 0 & 0.043152 \\
\hline & Oxidoreductase activity & 47 & 14 & 41 & 3 & 10 & 1 & 2.03E-04 \\
\hline & Cofactor binding & 23 & 9 & 23 & 2 & 8 & 0 & 0.001491 \\
\hline & Cargo receptor activity & 4 & 3 & 4 & 0 & 0 & 0 & 0.001611 \\
\hline & Chemokine receptor binding & 5 & 0 & 1 & 0 & 4 & 0 & 0.002826 \\
\hline & Coenzyme binding & 15 & 4 & 12 & 1 & 3 & 0 & 0.008153 \\
\hline & G-protein coupled receptor binding & 5 & 0 & 1 & 0 & 4 & 0 & 0.012537 \\
\hline & Motor activity & 12 & 2 & 9 & 0 & 1 & 0 & 0.012498 \\
\hline & Metalloexopeptidase activity & 0 & 2 & 2 & 3 & 0 & 0 & 0.013723 \\
\hline & Metallocarboxypeptidase activity & 0 & 2 & 1 & 3 & 0 & 0 & 0.036387 \\
\hline & Tetrapyrrole binding & 4 & 4 & 7 & 1 & 4 & 0 & 0.029038 \\
\hline & Cytokine activity & 5 & 0 & 1 & 0 & 4 & 0 & 0.033712 \\
\hline & Peroxiredoxin activity & 4 & 0 & 1 & 0 & 0 & 0 & 0.037208 \\
\hline & Adenylylsulfate kinase activity & 2 & 1 & 2 & 0 & 0 & 0 & 0.044538 \\
\hline
\end{tabular}

oxygenated intermediates (ROMs), which can cause genotoxicity and mutation by covalently binding to nucleic acids and proteins, CYPs can trigger tumor development [46]. In this study, the expression of the CYP1A1 gene was downregulated from 6 to $96 \mathrm{hpi}$, except at $72 \mathrm{hpi}$, and the GSTA2 gene was upregulated from 18 to 96 hpi. While downregulated CYP1A1 can reduce the production of ROMs, thus minimizing DNA and protein damage, the upregulation of GSTA2 may allow cytotoxic xenobiotics to accumulate, possibly triggering tumor development. This may be a mechanism via which $T$. gondii contributes to the development of some forms of cancer [47].
The expression of UGT1A was decreased from 12 to $96 \mathrm{hpi}$; however, no significant change in the gene expression was observed at $6 \mathrm{hpi}$. The UGT1A1 enzyme can detoxify many endogenous and exogenous compounds [48]. For example, irinotecan is widely used for the treatment of metastatic colorectal cancer and is metabolized by esterase to form a SN-38, which is further conjugated to UGT1A1. Patients with the UGT1A1 variant have poor metabolism of $\mathrm{SN}-38$ and are thus prone to irinotecan toxicity because of the difficulty of $\mathrm{SN}-38$ excretion from body in the non-toxic SN-38G form [49]. It is possible to hypothesize that cancer patients concurrently infected with $T$. gondii, if administered irinotecan, 


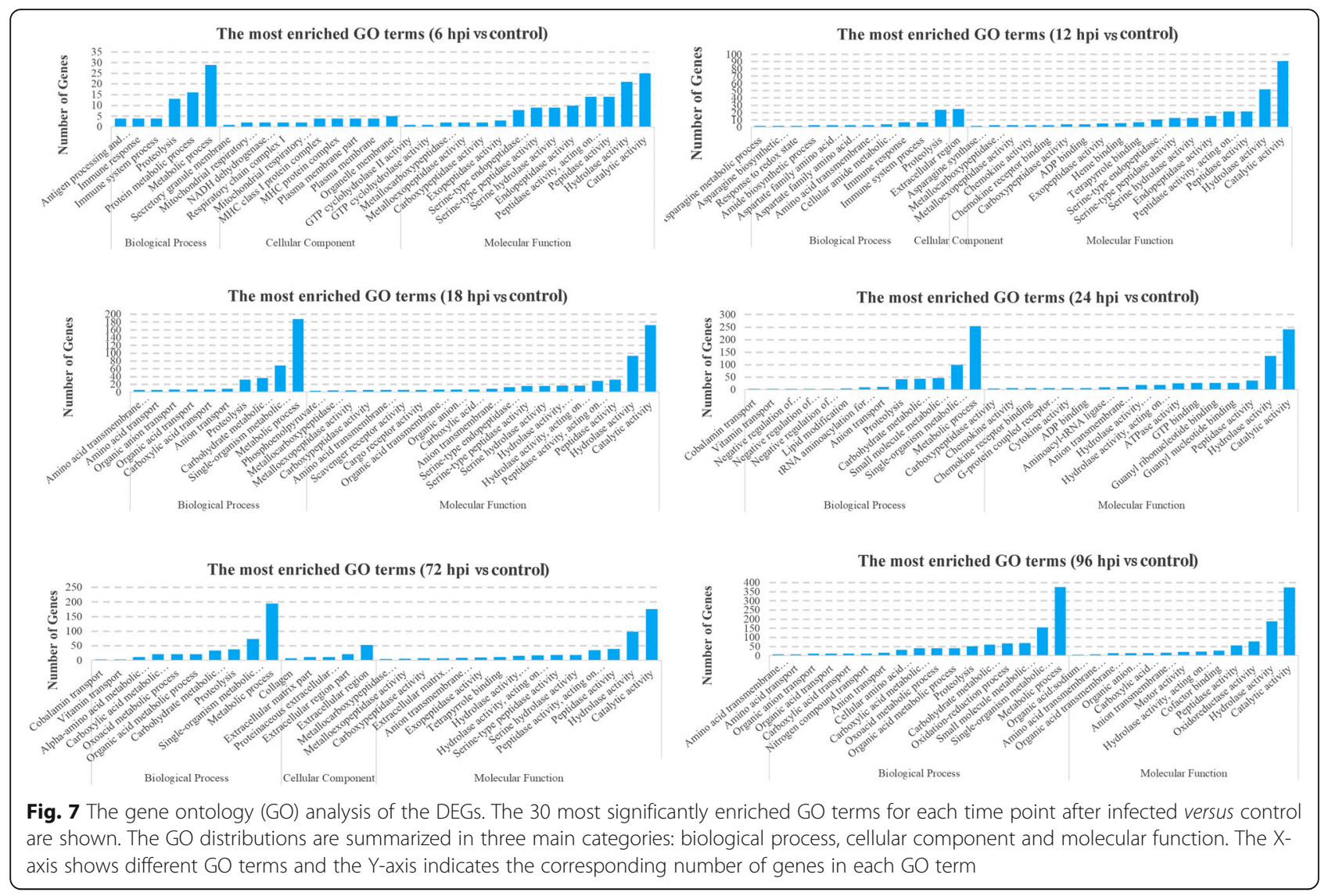

may experience serious toxicity due to limited detoxification and increased accumulation of SN-38 caused by reduced expression of $U G T 1 A$. The expression of $U G T 1 A$ during the $T$. gondii-host interaction raises a new question about the potential impact of parasite infection on irinotecan-treated cancer patients.

A link between $T$. gondii infection and Alzheimer's disease (AD) has also been previously suggested [50-52]. We were intrigued by the observation that the neutral endopeptidase $(N E P)$, amyloid- $\beta$ precursor protein $(A P P)$ and $A P O E$ genes were significantly downregulated at 24,72 and $96 \mathrm{hpi}$, respectively. The altered expression of the $N E P$, $A P P$ and $A P O E$ genes may impact the metabolism of endogenous amyloid- $\beta$, putatively a main contributor to $A D$ [53-55]. Here, the downregulation of NEP, APP and APOE genes at 24, 72 and 96 hpi suggests diverse means by which early $T$. gondii may contribute to the development of AD. In this study, we have not quantified the extent of $T$. gondii infection in each cat, nor considered the impact of parasite burden on the hosts' response. Therefore, the differences in host transcript abundance, observed over the course of infection, might have been influenced by changes in parasite burden or changes in parasite life stage development. Quantification of parasite burden, either through qPCR or analyzing parasite reads in RNA-Seq data, should be used to address this issue in future investigations. In addition, looking at differences in host transcript abundance during parasite life stage transitions throughout the course of infection, may provide critical insights in to how the feline host supports sexual reproduction.

\section{Conclusions}

Whole-transcriptome profiling, using RNA-Seq technology, of the cat's intestine following infection with T. gondii improved our understanding of the signaling pathways that mediate the response of cat intestine to early infection. Comparing the infection groups to the PBS-treated control group, 56, 184, 404, 508, 400 and 811 significantly DEGs were identified at $6,12,18,24$, 72 and 96 hpi, respectively. Our data suggest that $T$. gondii can modulate immune response and metabolic pathway to facilitate its development and survival in cat intestine. At 6 and $12 \mathrm{hpi}$, downregulation of MHC I genes may contribute to the establishment of infection in cat intestine during this early stage of host-parasite interaction. To counter the infection, the cat leverages chaperones, immunoproteasomes and transporters, through the upregulation of HSP70/90, PA28, TAP, and 


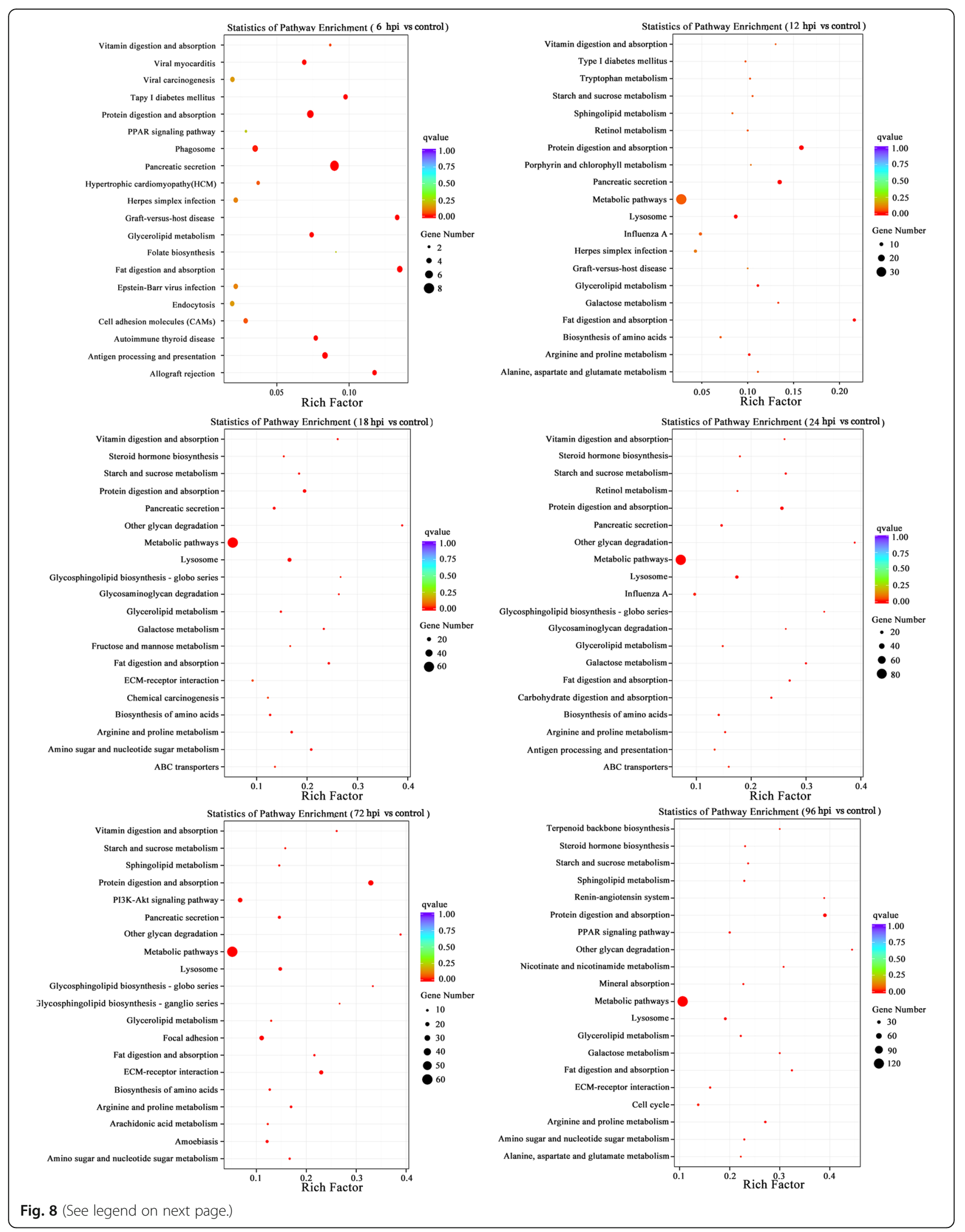


(See figure on previous page.)

Fig. 8 Scatter plots of the enriched KEGG pathways statistics. The $q$-value is the corrected $P$-value (range from 0 to 1). The colour and size of the dots represent the range of the $q$-value (level of significance) and the number of DEGs mapped to the indicated pathways, respectively. The X-axis shows the enrichment factor; the Y-axis corresponds to the KEGG Pathway. The top 20 enriched KEGG pathways of the indicated groups are shown. Rich factor is the ratio of the DEG number to the total gene number in a certain pathway

Table 3 Total differentially expressed KEGG pathways overrepresented/enriched by the differentially expressed genes in cat intestine in response to infection with $T$. gondii

\begin{tabular}{|c|c|c|c|c|c|c|c|}
\hline \multirow[t]{2}{*}{ KEGG pathway } & \multicolumn{6}{|c|}{ Gene number } & \multirow{2}{*}{$\begin{array}{l}\text { FDR } \\
\text { corrected } \\
P \text {-value }\end{array}$} \\
\hline & Cluster 1 & Cluster 2 & Cluster 3 & Cluster 4 & Cluster 5 & Cluster 6 & \\
\hline Protein digestion and absorption & 1 & 16 & 1 & 10 & 7 & 1 & $2.66 \mathrm{E}-15$ \\
\hline Lysosome & 3 & 9 & 1 & 13 & 0 & 1 & 4.44E-06 \\
\hline Mineral absorption & 0 & 10 & 1 & 3 & 0 & 0 & $5.75 \mathrm{E}-05$ \\
\hline ECM-receptor interaction & 0 & 13 & 1 & 5 & 0 & 0 & 0.000222 \\
\hline Pancreatic secretion & 4 & 6 & 0 & 0 & 9 & 0 & 0.000232 \\
\hline Galactose metabolism & 2 & 2 & 1 & 6 & 0 & 0 & 0.000677 \\
\hline Other glycan degradation & 0 & 3 & 0 & 5 & 0 & 0 & 0.001051 \\
\hline Amino sugar and nucleotide sugar metabolism & 2 & 4 & 1 & 6 & 0 & 0 & 0.001526 \\
\hline Arginine biosynthesis & 1 & 2 & 1 & 4 & 0 & 0 & 0.002527 \\
\hline Bile secretion & 1 & 8 & 2 & 3 & 0 & 0 & 0.00304 \\
\hline Alanine, aspartate and glutamate metabolism & 1 & 4 & 2 & 3 & 0 & 0 & 0.003204 \\
\hline Retinol metabolism & 2 & 4 & 0 & 4 & 0 & 0 & 0.005355 \\
\hline Focal adhesion & 4 & 14 & 1 & 7 & 0 & 0 & 0.010981 \\
\hline Starch and sucrose metabolism & 0 & 2 & 1 & 5 & 1 & 0 & 0.011597 \\
\hline Sphingolipid metabolism & 0 & 4 & 1 & 5 & 0 & 0 & 0.013042 \\
\hline Cell cycle & 17 & 0 & 1 & 0 & 0 & 0 & 0.014158 \\
\hline Carbohydrate digestion and absorption & 0 & 2 & 1 & 5 & 1 & 0 & 0.014633 \\
\hline Proximal tubule bicarbonate reclamation & 1 & 5 & 1 & 0 & 0 & 0 & 0.014947 \\
\hline Arginine and proline metabolism & 1 & 5 & 0 & 4 & 0 & 0 & 0.01764 \\
\hline Glycosaminoglycan degradation & 1 & 1 & 0 & 4 & 0 & 0 & 0.01764 \\
\hline$A B C$ transporters & 2 & 5 & 0 & 2 & 0 & 0 & 0.021963 \\
\hline Glycosphingolipid biosynthesis - globo series & 0 & 1 & 0 & 4 & 0 & 0 & 0.023611 \\
\hline Steroid hormone biosynthesis & 1 & 2 & 1 & 3 & 0 & 1 & 0.024807 \\
\hline Fructose and mannose metabolism & 1 & 4 & 1 & 2 & 0 & 0 & 0.024807 \\
\hline Glycolysis / Gluconeogenesis & 2 & 5 & 1 & 3 & 0 & 0 & 0.024807 \\
\hline Chemical carcinogenesis & 1 & 6 & 0 & 2 & 0 & 0 & 0.024807 \\
\hline Glutathione metabolism & 3 & 5 & 1 & 0 & 0 & 0 & 0.024807 \\
\hline Steroid biosynthesis & 6 & 0 & 0 & 0 & 0 & 0 & 0.025842 \\
\hline Drug metabolism - cytochrome P450 & 1 & 6 & 0 & 1 & 0 & 0 & 0.025842 \\
\hline Complement and coagulation cascades & 6 & 2 & 3 & 1 & 0 & 0 & 0.026353 \\
\hline p53 signaling pathway & 6 & 2 & 3 & 0 & 0 & 0 & 0.026976 \\
\hline Glycine, serine and threonine metabolism & 4 & 1 & 2 & 1 & 0 & 0 & 0.027354 \\
\hline Renin-angiotensin system & 1 & 3 & 0 & 2 & 0 & 0 & 0.027354 \\
\hline Pyrimidine metabolism & 10 & 1 & 2 & 0 & 0 & 0 & 0.03345 \\
\hline Amoebiasis & 3 & 7 & 0 & 4 & 0 & 0 & 0.034505 \\
\hline Nitrogen metabolism & 3 & 0 & 1 & 1 & 0 & 0 & 0.034505 \\
\hline
\end{tabular}


TAP1/2 genes, in order to promote potent antigen-specific immunity. Interestingly, $T$. gondii altered the expression of genes which may have relevance to other processes, such as xenobiotic metabolism and the pathogenesis of $\mathrm{AD}$. Elucidation of the roles of these pathways in the protective immunity against $T$. gondii infection may reveal new targets for vaccine design and therapeutic interventions to break the parasite transmission cycle in the definitive host.

\section{Additional files}

Additional file 1: Table S1. Temporal changes in the number of the differentially expressed genes by cat chromosomes. (XLSX $12 \mathrm{~kb}$ )

Additional file 2: Table S2. Differentially expressed genes at 6, 12, 18, 24, 72 and 96 hours post-infection (hpi) compared with the control, uninfected cats. (XLSX $259 \mathrm{~kb})$

\section{Abbreviations}

AD: Alzheimer's disease; AIDS: Acquired immune deficiency syndrome; APOE: Apolipoprotein E; APP: Amyloid precursor protein; CYPs: Cytochrome P450s; DC: Dendritic cells; DEGs: Differentially expressed genes; ER: Endoplasmic reticulum; FABPs: Fatty acid binding proteins; FDR: False discovery rate; GO: Gene ontology; GSTs: Glutathione S-transferases; hpi: Hours post-infection; HSP70: 70 kilodalton heat-shock proteins; HSP90: 90 kilodalton heat-shock proteins; IEL: Intraepithelial T lymphocytes; IFN-Y: Gamma interferon; IL 4/5/13/17: Interleukin 4/5/13/17; ILC: Innate lymphoid cells; KEGG: Kyoto Encyclopedia of Genes and Genomes; LP: Lamina propria; M cells: Microfold cells; MAT: Modified agglutination test; MHC I: Major histocompatibility complex I; NEP: Neutral endopeptidase; NK: Natural killer cells; PBS: Phosphate buffered saline; PPARs: Peroxisome proliferator-activated receptors; PSEN1: Presenilin-1 gene; PSEN2: Presenilin-2 gene; qRT-PCR: Quantitative reverse-transcribed polymerase chain reaction; RNA-Seg: RNA sequencing; ROMs: Reactive oxygenated intermediates; TAP: A transporter associated with antigen processing; TCR: T cell receptor; UGT1A1: Uridine diphosphate glucuronosyltransferase A1

\section{Acknowledgements}

The authors would like to thank Novogene Bioinformatics Technology Co., Ltd (Beijing, China) for performing the sequencing and preliminary computational analysis.

\section{Funding}

Project support was provided by the International Science and Technology Cooperation Project of Gansu Provincial Key Research and Development Program (grant no. 17JR7WA031), the National Natural Science Foundation of China (grant no. 31230073), the Elite Program of Chinese Academy of Agricultural Sciences, and the Agricultural Science and Technology Innovation Program (ASTIP) (grant no. CAAS-ASTIP-2016-LVRI-03).

\section{Availability of data and materials}

The data supporting the findings of this article are included within the article and its additional files. The RNA-Seq raw data have been submitted to the NCBI SRA repository under accession numbers SAMN09381735-SAMN09381741.

\section{Authors' contributions}

$\mathrm{XQZ}, \mathrm{JXL}, J \mathrm{JH}$ and HME conceived and designed the study, and critically revised the manuscript. MW and FKZ performed the experiment, analyzed the transcriptomic data and drafted the manuscript. HME, NZZ and JJH helped in data analysis and manuscript revision. All authors read and approved the final manuscript.

\section{Ethics approval and consent to participate}

This study was conducted in accordance with the recommendations set forth in the Animal Ethics Procedures and Guidelines of the People's Republic of China. Animal experiments were reviewed and approved by the
Animal Administration and Ethics Committee of Lanzhou Veterinary Research Institute, Chinese Academy of Agricultural Sciences. All efforts were made to minimize the number of animals used and their suffering.

\section{Consent for publication}

Not applicable.

\section{Competing interests}

The authors declare that they have no competing interests.

\section{Publisher's Note}

Springer Nature remains neutral with regard to jurisdictional claims in published maps and institutional affiliations.

\section{Author details}

'State Key Laboratory of Veterinary Etiological Biology, Key Laboratory of Veterinary Parasitology of Gansu Province, Lanzhou Veterinary Research Institute, Chinese Academy of Agricultural Sciences, Lanzhou, Gansu Province 730046, People's Republic of China. ${ }^{2}$ Faculty of Medicine and Health Sciences, School of Veterinary Medicine and Science, University of Nottingham, Sutton Bonington Campus, Loughborough LE12 5RD, UK. ${ }^{3}$ Jiangsu Co-innovation Center for the Prevention and Control of Important Animal Infectious Diseases and Zoonoses, Yangzhou University College of Veterinary Medicine, Yangzhou, Jiangsu Province 225009, People's Republic of China.

Received: 17 July 2018 Accepted: 29 October 2018

Published online: 14 November 2018

References

1. Dubey JP. Toxoplasmosis of Animals and Humans. Boca Raton: CRC Press; 2010.

2. Dubey JP, Miller NL, Frenkel JK. The Toxoplasma gondii oocyst from cat feces. J Exp Med. 1970;132:636-62.

3. Dubey JP. History of the discovery of the life cycle of Toxoplasma gondii. Int J Parasitol. 2009;39:877-82.

4. Dubey JP. Toxoplasma gondii oocyst survival under defined temperatures. J Parasitol. 1998;84:862-5.

5. Lindsay DS, Dubey JP. Long-term survival of Toxoplasma gondii sporulated oocysts in seawater. J Parasitol. 2009;95:1019-20.

6. Jones JL, Dubey JP. Waterborne toxoplasmosis - recent developments. Exp Parasitol. 2010;124:10-25

7. Jones JL, Dubey JP. Foodborne toxoplasmosis. Clin Infect Dis. 2012;55:845-51.

8. Dubey JP, Prowell M. Ante-mortem diagnosis, diarrhea, oocyst shedding, treatment, isolation, and genetic typing of Toxoplasma gondii associated with clinical toxoplasmosis in a naturally infected cat. J Parasitol. 2013;99:158-60.

9. Montoya JG, Liesenfeld O. Toxoplasmosis. Lancet. 2004;363:1965-76.

10. Torrey EF, Yolken RH. Toxoplasma oocysts as a public health problem. Trends Parasitol. 2013;29:380-4.

11. Shao $L$, Serrano D, Mayer $L$. The role of epithelial cells in immune regulation in the gut. Semin Immunol. 2001;13:163-76.

12. Haber AL, Biton M, Rogel N, Herbst RH, Shekhar K, Smillie C, et al. A singlecell survey of the small intestinal epithelium. Nature. 2017;551:333-9.

13. Liesenfeld O. Immune responses to Toxoplasma gondii in the gut. Immunobiology. 1999;201:229-39.

14. McLeod R, Estes RG, Mack DG, Cohen H. Immune response of mice to ingested Toxoplasma gondii: a model of toxoplasma infection acquired by ingestion. J Infect Dis. 1984;149:234-44.

15. McLeod R, Eisenhauer P, Mack D, Brown C, Filice G, Spitalny G. Immune responses associated with early survival after peroral infection with Toxoplasma gondii. J Immunol. 1989;142:3247-55.

16. Herrmann DC, Pantchev N, Vrhovec MG, Barutzki D, Wilking H, Frohlich A, et al. Atypical Toxoplasma gondii genotypes identified in oocysts shed by cats in Germany. Int J Parasitol. 2010;40:285-92.

17. Maksimov P, Zerweck J, Dubey JP, Pantchev N, Frey CF, Maksimov A, et al. Serotyping of Toxoplasma gondii in cats (Felis domesticus) reveals predominance of type II infections in Germany. PLoS One. 2013;8:e80213.

18. Brennan A, Donahoe SL, Beatty JA, Belov K, Lindsay S, Briscoe KA, et al. Comparison of genotypes of Toxoplasma gondii in domestic cats from Australia with latent infection or clinical toxoplasmosis. Vet Parasitol. 2016; 228:13-6. 
19. Cong W, Zhang XX, He JJ, Li FC, Elsheikha HM, Zhu XQ. Global miRNA expression profiling of domestic cat livers following acute Toxoplasma gondii infection. Oncotarget. 2017;8:25599-611.

20. Yan HK, Yuan ZG, Song HQ, Petersen E, Zhou Y, Ren D, et al. Vaccination with a DNA vaccine coding for perforin-like protein 1 and MIC6 induces significant protective immunity against Toxoplasma gondii. Clin Vaccine Immunol. 2012;19:684-9.

21. Trapnell C, Pachter L, Salzberg SL. TopHat: discovering splice junctions with RNA-Seq. Bioinformatics. 2009;25:1105-11.

22. Anders S, Huber W. Differential expression analysis for sequence count data. Genome Biol. 2010;11:R106

23. Young MD, Wakefield MJ, Smyth GK, Oshlack A. Gene ontology analysis for RNA-seq: accounting for selection bias. Genome Biol. 2010;11:R14.

24. Kanehisa M, Araki M, Goto S, Hattori M, Hirakawa M, Itoh M, et al. KEGG for linking genomes to life and the environment. Nucleic Acids Res. 2008;36: D480-4.

25. Mao X, Cai T, Olyarchuk JG, Wei L. Automated genome annotation and pathway identification using the KEGG Orthology $(\mathrm{KO})$ as a controlled vocabulary. Bioinformatics. 2005:21:3787-93.

26. Behnke MS, Zhang TP, Dubey JP, Sibley LD. Toxoplasma gondii merozoite gene expression analysis with comparison to the life cycle discloses a unique expression state during enteric development. BMC Genomics. 2014; 15:350.

27. Piekarski G, Pelster B, Witte HM. Endopolygeny in Toxoplasma gondii. Z Parasitenkd. 1971;36:122-30 (In German).

28. Hehl AB, Basso WU, Lippuner C, Ramakrishnan C, Okoniewski M, Walker RA, et al. Asexual expansion of Toxoplasma gondii merozoites is distinct from tachyzoites and entails expression of non-overlapping gene families to attach, invade, and replicate within feline enterocytes. BMC Genomics. 2015;16:66.

29. Blanchard N, Gonzalez F, Schaeffer M, Joncker NT, Cheng T, Shastri AJ, et al. Immunodominant, protective response to the parasite Toxoplasma gondii requires antigen processing in the endoplasmic reticulum. Nat Immunol. 2008;9:937-44

30. Buaillon C, Guerrero NA, Cebrian I, Blanie S, Lopez J, Bassot E, et al. MHC I presentation of Toxoplasma gondii immunodominant antigen does not require $\operatorname{Sec} 22 \mathrm{~b}$ and is regulated by antigen orientation at the vacuole membrane. Eur J Immunol. 2017;47:1160-70.

31. Khan IA, Ely KH, Kasper LH. Antigen-specific CD8+ T cell clone protects against acute Toxoplasma gondii infection in mice. J Immunol. 1994;152: 1856-60.

32. Preckel T, Fung-Leung WP, Cai Z, Vitiello A, Salter-Cid L, Winqvist O, et al. Impaired immunoproteasome assembly and immune responses in PA28-/- mice. Science. 1999;286:2162-5.

33. Combe CL, Curiel TJ, Moretto MM, Khan IA. NK cells help to induce CD8(+)-T-cell immunity against Toxoplasma gondii in the absence of CD4(+) T cells. Infect Immun. 2005;73:4913-21.

34. MacMicking JD. Interferon-inducible effector mechanisms in cellautonomous immunity. Nat Rev Immunol. 2012;12:367-82.

35. Kloetzel PM. Antigen processing by the proteasome. Nat Rev Mol Cell Bio. 2001;2:179-87

36. Rock KL, Goldberg AL. Degradation of cell proteins and the generation of MHC class I-presented peptides. Annu Rev Immunol. 1999;17:739-79.

37. Bougneres $L$, Helft J, Tiwari $S$, Vargas $P$, Chang $B H$, Chan $L$, et al. A role for lipid bodies in the cross-presentation of phagocytosed antigens by $\mathrm{MHC}$ class I in dendritic cells. Immunity. 2009:31:232-44.

38. Milani V, Noessner E, Ghose S, Kuppner M, Ahrens B, Scharner A, et al. Heat shock protein 70: role in antigen presentation and immune stimulation. Int J Hyperthermia. 2002;18:563-75.

39. Castellino F, Boucher PE, Eichelberg K, Mayhew M, Rothman JE, Houghton $A N$, et al. Receptor-mediated uptake of antigen/heat shock protein complexes results in major histocompatibility complex class I antigen presentation via two distinct processing pathways. J Exp Med. 2000;191: 1957-64.

40. Srivastava P. Interaction of heat shock proteins with peptides and antigen presenting cells: chaperoning of the innate and adaptive immune responses. Annu Rev Immunol. 2002;20:395-425.

41. Garrido C, Brunet M, Didelot C, Zermati Y, Schmitt E, Kroemer G. Heat shock proteins 27 and 70: anti-apoptotic proteins with tumorigenic properties. Cell Cycle. 2006;5:2592-601.

42. Wegele H, Muller L, Buchner J. Hsp70 and Hsp90 - a relay team for protein folding. Rev Physiol Biochem Pharmacol. 2004;151:1-44.
43. Speer CA, Dubey JP. Ultrastructural differentiation of Toxoplasma gondii schizonts (types B to E) and gamonts in the intestines of cats fed bradyzoites. Int J Parasitol. 2005;35:193-206.

44. Guiton PS, Sagawa JM, Fritz HM, Boothroyd JC. An in vitro model of intestinal infection reveals a developmentally regulated transcriptome of Toxoplasma sporozoites and a NF-kappaB-like signature in infected host cells. PLoS One. 2017:12:e0173018.

45. Furuhashi M, Hotamisligil GS. Fatty acid-binding proteins: role in metabolic diseases and potential as drug targets. Nat Rev Drug Discov. 2008;7:489-503.

46. Nebert DW, Dalton TP. The role of cytochrome P450 enzymes in endogenous signalling pathways and environmental carcinogenesis. Nat Rev Cancer. 2006;6:947-60

47. Cong W, Liu GH, Meng QF, Dong W, Qin SY, Zhang FK, et al. Toxoplasma gondii infection in cancer patients: prevalence, risk factors, genotypes and association with clinical diagnosis. Cancer Lett. 2015;359:307-13.

48. Tukey RH, Strassburg CP. Human UDP-glucuronosyltransferases: metabolism, expression, and disease. Annu Rev Pharmacol. 2000;40:581-616.

49. O'Dwyer PJ, Catalano RB. Uridine diphosphate glucuronosyltransferase(UGT)1A1 and irinotecan: practical pharmacogenomics arrives in cancer therapy. J Clin Oncol. 2006;24:4534-8.

50. Kusbeci OY, Miman O, Yaman M, Aktepe OC, Yazar S. Could Toxoplasma gondii have any role in Alzheimer disease? Alzheimer Dis Assoc Disord. 2011;25:1-3

51. Mahami-Oskouei M, Hamidi F, Talebi M, Farhoudi M, Taheraghdam AA, Kazemi T, et al. Toxoplasmosis and Alzheimer: can Toxoplasma gondii really be introduced as a risk factor in etiology of Alzheimer? Parasitol Res. 2016; 115:3169-74.

52. Perry CE, Gale SD, Erickson L, Wilson E, Nielsen B, Kauwe J, et al. Seroprevalence and serointensity of latent Toxoplasma gondii in a sample of elderly adults with and without Alzheimer disease. Alzheimer Dis Assoc Disord. 2016:30:123-6.

53. Iwata N, Tsubuki S, Takaki Y, Watanabe K, Sekiguchi M, Hosoki E, et al. Identification of the major Abeta1-42-degrading catabolic pathway in brain parenchyma: suppression leads to biochemical and pathological deposition. Nat Med. 2000;6:143-50.

54. Zhang YW, Thompson R, Zhang H, Xu H. APP processing in Alzheimer's disease. Mol Brain. 2011:4:3.

55. Canter RG, Penney J, Tsai LH. The road to restoring neural circuits for the treatment of Alzheimer's disease. Nature. 2016:539:187-96.

\section{Ready to submit your research? Choose BMC and benefit from:}

- fast, convenient online submission

- thorough peer review by experienced researchers in your field

- rapid publication on acceptance

- support for research data, including large and complex data types

- gold Open Access which fosters wider collaboration and increased citations

- maximum visibility for your research: over $100 \mathrm{M}$ website views per year

At $\mathrm{BMC}$, research is always in progress.

Learn more biomedcentral.com/submissions 